\title{
A NEW ALTERNATIVE QUAC-STICK TO PREDICT THE RISK OF CHRONIC ENERGY DEFICIENCY IN MALAY INDONESIAN WOMEN (18-49 YEARS)
}

\author{
Ummi Kalsum¹), Bambang Sutrisna2), Ratna Djuwita²), \\ Endang L Achadi'), Abas Basuni Jahari3) \\ 1)Public Health Study Program, Faculty of Medicine and \\ Health Science, University of Jambi \\ 2)Faculty of Public Health, Universitas Indonesia, Jakarta \\ 3)National Institute of Health Research and Development, \\ Ministry of Health, Jakarta
}

\begin{abstract}
BACKGROUND: Indicators to assess the nutritional status in women of reproductive age (WRA) in particular to identify chronic energy deficiency (CED) were still limited. Upper arm circumference (MUAC) and the Body Mass Index (BMI) had been used to assess the status of CED, but it still has its limitations. This study aimed to develop a new indicator QUACStick (the ratio of MUAC to Upper Arm Length (UAL)) for the risk asesement of CED on WRA in Malay Indonesia women (18-49 years).

SUBJECT AND METHODS: The cross sectional study design, used a part of data from National Basic Health Research (Riskesdas) 2013 and primary collecting data among 1009 WRA aged 18-49 years (not pregnant) in Makassar and Tana Toraja, South Sulawesi Province. Analysis used the ROC to get the optimal formula and the cut off point using BMI as the gold standard.

Results: MUAC/ UAL (named UMMI index) with a cut-off point $<4.25$ to detect the risk of $\mathrm{CED}$, had better validity ( $\mathrm{Sn}=80 \%$ (95\% $\mathrm{CI}=70.8$ to 87.3 ); $\mathrm{Sp}=84 \%$ (95\% CI $=81.4$ to 86.3$) ; \mathrm{PPV}=35 \%(95 \% \mathrm{CI}=29.2$ to 42.0); $\mathrm{NPV}=97 \%$ ( $95 \% \mathrm{CI}=96.1$ to $98.4 ; \mathrm{ROC}=82 \%(95 \% \mathrm{CI}=80.0$ to 86.1) compared to MUAC < 23,5 with the gold standard was BMI <18.5.

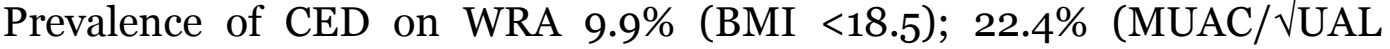
$<4.25)$. The validity of MUAC < 23.5 was $\operatorname{good}(\mathrm{Sn}=76 \%$, Sp $=87.2 \%)$, but the optimal cut-off point for screening was MUAC $<=24.0 \mathrm{~cm}(\mathrm{Sn}=90 \%$, $\mathrm{Sp}=77 \%)$. The correlation ( $\mathrm{r}$ ) between MUAC-weight $=0.82$; UAL-Height $=0.45 ; \mathrm{MUAC}-\mathrm{BMI}=0.82$ and $\mathrm{MUAC} / \sqrt{ } \mathrm{UAL}$ to $\mathrm{BMI}=0.80(\mathrm{P}=0.000)$.

Conclusion: The new alternative indicator was $\mathrm{MUAC} / \sqrt{\mathrm{UAL}}<4.25$ to assess the risk of CED on WRA in Malay Indonesia women (18-49 years). Further revalidation study is needed to be able applying the indicator to the wider population.
\end{abstract}

Keywords: Ratio, MUAC, Women of reproductive, CED, Arm Length 